\title{
Entre a fuga e a invasão: alteridade e cidadania da imigração haitiana na mídia brasileira
}

\section{Between escape and invasion: otherness and citizenship of Haitian immigration in the Brazilian media}

\section{Denise Cogo}

Doutora em Ciências da Comunicação na Universidade de São Paulo. Pós-Doutorado na Universidade Autônoma de Barcelona. Pesquisadora Produtividade 1D do CNPq (Conselho Nacional de Desenvolvimento Científico e Tecnológico). Professora Titular do Programa de Pós-Graduação em Comunicação e Práticas de Consumo da ESPM-SP.

<denisegogo2@gmail.com>

\section{Terezinha Silva}

Doutora em Comunicação Social na Universidade Paris Ouest Nanterre (França) e Universidade Federal de Minhas Gerais (Brasil), através de convênio de cotutela. Professora Colaboradora do Departamento de Comunicação Social da UFMG (Universidade Federal de Minas Gerais). Pesquisadora associada ao GRIS - Grupo de Pesquisa em Imagem e Sociabilidade (PPGCOM/UFMG). $<$ terezinhasilva@yahoo.com>

\section{RESUMO}

O artigo analisa o tratamento dado à imigração de haitianos pela mídia brasileira nos primeiros quatro anos de presença significativa da diáspora haitiana no Brasil (2011- 2014). Busca compreender como se instauram, nas mídias, disputas de sentido em torno da alteridade representada pela presença desses novos imigrantes, assim como as incidências da visibilidade midiática dos imigrantes haitianos no debate público sobre as políticas migratórias e processos de cidadania das migrações internacionais no Brasil. A partir do conceito de enquadramento, analisou-se, um corpus de 162 materiais midiáticos, acontecimentos e temas mapeados na produção midiática sobre a imigração haitiana. Constatou-se a mudança de enquadramento na cobertura midiática desta imigração - inicialmente descrita como "fuga" do Haiti e posteriormente como "invasão" ao Brasil - e a emergência de um debate que questiona a política migratória brasileira e os processos de cidadania de haitianos no Brasil.

Palavras-chave: Mídia. Imigração haitiana. Cidadania.

\section{ABSTRACT}

The article analyzes the treatment given to migration of Haitians by the Brazilian media in the first four years of significant presence of the Haitian diaspora in Brazil (2011-2014). Seeks to understand how are established, in the media, sense of disputes over otherness represented by the presence of these new immigrants, and the impact of media visibility of Haitian immigrants in the public debate on migration policies and processes of citizenship of international migration in Brazil. Using the concept of framing, it was analyzed a corpus of 162 media materials, events and themes mapped in media production about Haitian immigration. It was found the change of framing in the media coverage of this immigration - initially described as "escape" of Haiti and later as "invasion" to Brazil - and the emergence of a debate that rise questions on Brazilian immigration policy and Haitian citizenship processes in Brazil.

Keywords: Media. Haitian immigration. Citizenship.

\section{Introdução}

A partir do início do ano de 2011, um movimento migratório com escassa presença na história brasileira - a imigração haitiana - ganhou notoriedade 
pública a partir de um intenso fluxo de informações e imagens produzidas e difundidas pela mídia brasileira em torno de seu ingresso através da fronteira da região norte do Brasil. A novidade do fenômeno, as trajetórias assumidas por essa imigração e os desdobramentos de sua presença no debate público em torno das políticas migratórias e dos processos de cidadania das migrações internacionais no país vão assumir visibilidade, especialmente a partir a intensificação dessas narrativas midiáticas que enunciam as dinâmicas de chegada e inserção de haitianos no Brasil.

O presente trabalho tem como objetivo, mapear e compreender como a imigração haitiana foi abordada por diferentes mídias ou por narrativas que nelas ganharam visibilidade nos primeiros quatro anos de presença significativa da diáspora haitiana no Brasil (2011-2014). Interessa-nos, mais especificamente, apreender as disputas de sentido em torno da alteridade representada pela presença desses novos imigrantes e suas repercussões no debate público sobre as políticas migratórias e processos de cidadania das migrações internacionais no país.

Três questões orientam a reflexão aqui proposta: 1) Quais acontecimentos e/ou temas relativos à imigração haitiana ganham algum tipo de visibilidade na agenda público-midiática? 2) Como, em sua condição de alteridade, a imigração haitiana e os imigrantes são descritos ou enquadrados no contexto desses acontecimentos e temas visibilizados pelas mídias? 3) Como os acontecimentos e temas agendados trazem ao debate público dimensões que evidenciam disputas em torno das políticas migratórias brasileiras como instâncias de constituição da cidadania da imigração haitiana e das migrações internacionais em geral?

A metodologia abrangeu a coleta e análise de um corpus de 162 materiais midiáticos, em versão digital, sobre a imigração haitiana publicados em portais, jornais, revistas, blogs, sites de redes sociais, vinculados a organizações midiáticas públicas e privadas, assim como em publicações mantidas por instituições públicas, privadas e sem fins lucrativos - todos referenciados ao final do artigo. Entendemos que esse conjunto de materiais midiáticos, selecionados, são representativos dos principais acontecimentos e temas ofertados pela mídia brasileira sobre a imigração haitiana, inclusive em termos de pluralidade temáti- 
ca. Contudo, não pretendemos dar conta (e nem poderíamos) de todo o escopo de publicações midiáticas sobre a mobilidade haitiana, tendo em vista o crescimento da produção sobre essa imigração nas mídias nos últimos quatros anos.

A análise foi desenvolvida a partir da leitura e categorização temática das matérias coletadas, e da identificação dos acontecimentos e temas que pautaram a construção da imigração haitiana na mídia brasileira. Compreendemos a noção de acontecimento como algo que emerge ou provoca uma ruptura na continuidade da experiência, que provoca ações e discursos por parte de indivíduos e instituições, revelando problemas, temas, questões da vida coletiva, conforme a abordagem proposta por Quéré (2005). Nesse sentido, entendemos a chegada dos imigrantes haitianos ao Brasil, assim como outras ocorrências a ela relacionadas, como acontecimentos, que interpelam e agenciam diferentes atores, instituições e discursos em torno de questões coletivas que essa imigração suscita.

Através de uma análise qualitativa do conteúdo das 162 matérias, identificamos um total de sete acontecimentos e temas, relacionados à imigração haitiana e abordados pelas mídias, de modo central ou exclusivo, ou de maneira articulada, de 2010 a 2014'. Desse conjunto de acontecimentos e temas que compuseram a agenda midiática do período analisado, selecionamos três para a análise: a chegada dos imigrantes ao Brasil; o fechamento do abrigo em Brasiléia (Acre) e a chegada de haitianos a São Paulo; e a política migratória brasileira, tendo como operador analítico o conceito de enquadramento, explicitado mais adiante. Tal redução deveu-se não apenas à limitação de espaço do presente artigo, mas também, à observação de que, no conjunto do material coletado, foram os que mais ganharam repercussão e desdobramentos na agenda midiática.

1 São eles:1) A chegada dos imigrantes ao Brasil, ocorrida em diferentes momentos; 2) A "situação de emergência social" no estado do Acre, decretada em 10 de abril de 2013; 3) O fechamento do abrigo em Brasiléia (Acre) e a chegada de haitianos a São Paulo, no começo de 2014, e a consequente polêmica instaurada entre os governos do Acre e de São Paulo; 4) A política migratória brasileira, abordada de modo central ou transversal em inúmeros materiais midiáticos a partir de meados de 2011 e, sobretudo, após 2012; 5) A inserção de haitianos no mercado laboral e denúncias de trabalho escravo; 6) A epidemia mundial de Ebola, tematizada em meados de 2014 através da cobertura de situações cotidianas de suspeita e discriminação vivenciadas por haitianos em cidades brasileiras;7) A inserção de haitianos no cotidiano da sociedade brasileira (cursos, aprendizado da língua portuguesa, esporte e cultura etc.). 


\section{Imigração haitiana no Brasil: contextualização}

A diáspora haitiana que, após o terremoto que atingiu o Haiti, em 2010, tornou-se realidade no Brasil, intensificou-se no início do século $\mathrm{XX}$, passando a ter presença relevante em distintas regiões do mundo, especialmente Caribe, América do Norte e Europa Ocidental. Estima-se que um milhão e meio de haitianos, cerca de $15 \%$ da população do país, residam, atualmente, no exterior. As primeiras migrações haitianas de grande amplitude coincidem com a ocupação militar do Haiti² pelos Estados Unidos entre 1915 e 1934, não podendo ser dissociadas da conjuntura geopolítica intervencionista que visava atender aos interesses econômicos estadunidenses no Caribe no início do século XX (Audebert, 2011).

Somam-se a isso, condições econômicas e políticas anteriores que, durante os séculos XVIII e XIX, também contribuíram para impulsionar fluxos migratórios de haitianos, a partir da implantação, no Haiti, de um sistema econômico de plantação de cana e de café que, às custas da exploração da força de trabalho e dos recursos naturais, visou à obtenção de rentabilidade máxima em curto prazo (Audebert, 2011). A sucessão de governos ditatoriais, golpes de estado e uma guerra civil que durou vários anos contribuíram para aprofundar, nas últimas décadas, as dificuldades socioeconômicas e políticas enfrentadas pela população haitiana. Soma-se a isso o terremoto que atingiu o país em 12 de janeiro de 2010, provocando cerca de 200 mil mortes e deixando cerca de 1,5 milhões de desabrigados.

Em maio de 2015, o Embaixador do Haiti no Brasil, Madsen Chérubin, informou que, até dezembro 2014, 53 mil haitianos haviam ingressado no país, cerca de 20 mil regularizados através de vistos humanitários ${ }^{3}$. Estudo realizado em 2014 pelo Observatório das Migrações Internacionais indica que, dentre os imigrantes internacionais, os haitianos já constituem, quantitativamente, a

2 Antiga colônia francesa e primeira República negra do mundo, o Haiti está localizado na América Central e possui uma população de mais de 10 milhões de habitantes. A exportação de açúcar, café e cacau permitiu que, durante o século XVIII, a região fosse a mais próspera colônia francesa da América. Foi, ainda, o $1^{\circ}$ país do mundo a abolir a escravidão, após uma revolta de escravos em 1793 , e o $2^{\circ}$ país das Américas a se tornar independente, em 1804.

3 Dados apresentados na mesa "Haiti Aqui", promovida pela ONG Viva Rio em 21 de maio de 2015, na Universidade Zumbi dos Palmares, em São Paulo, como atividade, Circuito Cultural Haiti Aqui de História e Arte. 
nacionalidade com maior presença no mercado de trabalho formal brasileiro (Cavalcanti, Oliveira e Tonhati, 2014).

O ingresso de haitianos no Brasil tem sido feito através de rotas, que incluem o deslocamento aéreo da República Dominicana ou de Porto Príncipe, para o Equador e, em alguns casos, por via terrestre para o Peru. Esse trajeto é seguido de um percurso, também terrestre, até as cidades de Assis Brasil, Epitaciolândia e Brasiléia (no estado do Acre) ou Tabatinga, (no estado do Amazonas). Em alguns casos, os imigrantes chegam também pela cidade de Corumbá, Mato Grosso do Sul ou, ainda, por aeroportos de grandes cidades brasileiras, como São Paulo (Cogo, 2014). As escolhas das rotas de ingresso estão condicionadas por variáveis como as facilidades e custos de transporte, as possibilidades efetivas de entrar no país, além de interesses e estratégias traçadas pelos "coiotes" ${ }^{4}$. Entre os imigrantes que chegam ao Brasil, predominam homens jovens entre os 25 aos 34 anos, embora, a partir de 2013, se observe também um aumento do número de mulheres, crianças e idosos que migram para o país (Ximenes e Almeida, 2014).

A mobilidade haitiana para o Brasil é um movimento migratório que se insere nas reconfigurações dos movimentos migratórios internacionais que têm se caracterizado por maior diversidade e multidirecionalidade. Nesse contexto, a partir de 2008, o Brasil passa a ocupar um específico posicionamento como país receptor de imigrantes, tornando-se novamente opção de grupos migratórios diversos, dentre os quais norte-americanos, espanhóis, portugueses, senegaleses e haitianos Esse reposicionamento vai decorrer especialmente da crise econômica global que, a partir de 2007, atingiu, de modo mais acentuado, Estados Unidos e Europa, assim como das possibilidades de trabalho abertas, no país, pela realização das obras de infraestrutura relacionadas aos grandes eventos como a Copa do Mundo de 2014 e as Olimpíadas de 2016 (Cogo, Souza, 2013).

O crescimento da imigração haitiana para o Brasil não pode, contudo, ser compreendido como decorrência unicamente do terremoto que agravou as já precárias condições de sobrevivência de grande parte da população haitiana.

4 Pessoas ou grupos que cobram para introduzir, de modo "ilegal", migrantes nas fronteiras entre países. 
Além da experiência diaspórica que demarca a trajetória do povo haitiano, é preciso considerar também a existência de vinculações geopolíticas e simbólicas anteriores entre Brasil e Haiti. Estas estão relacionadas, principalmente, à atuação, no Haiti, do exército brasileiro que, em 2004, assumiu o controle das tropas da Missão das Nações Unidas para a Estabilização do Haiti (MINUSTAH), e de organizações não governamentais (ONGs), prévia e posteriormente ao terremoto.

Assim, a visibilidade pública dessa imigração produzida pela mídia brasileira pode ser pensada como resultado e ao mesmo tempo instância que vai evidenciar e (re) atualizar esses enlaces geopolíticos e imaginários simbólicos entre Brasil e Haiti, que operam como antecedentes e também impulsionadores dos fluxos migratórios de haitianos para o país. A mídia vai atuar na produção e proposição de modos de vivenciar a alteridade nas interações entre esses novos imigrantes e a sociedade brasileira, se entendemos a noção de alteridade como um processo de constituição de subjetividades e identidades sociais que assume uma perspectiva classificatória e relacional. É na dinâmica de relação com o outro, na sua condição de "diferente", que se tecem as experiências de alteridade migratória. Estas são impactadas ao mesmo tempo em que impactam os discursos sobre os imigrantes e as políticas migratórias produzidos por diferentes instituições como as midiáticas, estatais, etc.

\section{Enquadramentos da imigração haitiana na mídia}

O enquadramento é um conceito útil para identificar as formas de interpretar ou significar um acontecimento, tema etc., e as disputas de sentido aí implicadas, além de permitir ver como os atores envolvidos são posicionados ou qualificados numa determinada situação. Entendemos esse conceito a partir das reflexões de Goffman (1991) sobre os "quadros da experiência", definidos como sendo "princípios de organização ou elementos de base que estruturam os acontecimentos [...], e servem para definir a situação e a nossa implicação neles" (Goffman,1991, p.19). Nesta perspectiva, conforme destacam França, Silva e Vaz (2014, p. 83), "os quadros são como matrizes interpretativas às quais os indivíduos recorrem cotidianamente para entender e se posicionar em diferentes situações. E o'enquadramento' é a mobilização desses quadros - um proces- 
so fundamental na organização da experiência", pois permite aos indivíduos definir o que acontece, para se posicionarem e atuarem em determinada situação. "Tais quadros, porém, não são construções individuais e sim socioculturais", que "os indivíduos mantêm, transformam, atualizam, em suas interações e relações sociais" (França, Silva e Vaz, 2014, p. 83).

No caso da imigração haitiana no Brasil, o conceito de enquadramento nos permite analisar como a alteridade representada por essa imigração é descrita e construída pela mídia na perspectiva de compreendermos as incidências desses quadros de sentido nos processos de cidadania e políticas migratórias relacionadas à imigração de haitianos e, de modo articulado, à imigração internacional no Brasil. É o que apresentamos na sequência a partir da análise da chegada dos imigrantes ao Brasil; do fechamento do abrigo em Brasiléia (Acre) e da chegada de haitianos a São Paulo; e do debate em torno da política migratória brasileira.

\section{A chegada dos haitianos como "fuga"}

Embora tenha iniciado a partir de fevereiro e, sobretudo, setembro de 2010 meses após o terremoto no Haiti -, a chegada de haitianos ao Brasil ganha visibilidade nas mídias brasileiras principalmente no começo de $2011^{5}$. Essa imigração é descrita, naquele momento, como "um fluxo migratório inédito" provocado pelas "consequências da tragédia" que foi o terremoto de janeiro de 2010 no Haiti (Rocha e Aranha, 2011). Trata-se, conforme as narrativas, da "chegada de Haitianos em fuga", que "surpreendeu o governo brasileiro", o qual "ainda não tem uma solução definitiva para os 700 Haitianos" que, em um ano, "atravessaram a fronteira empurrados pela catástrofe" e entraram no Brasil - "grande parte deles [...] ilegalmente" (Rocha e Aranha, 2011; Sabadini, 2011).

O título da reportagem da revista Época em 05/02/2011- "O que fazer com os haitianos?" (Rocha e Aranha, 2011) - prenuncia questionamentos que vão emergir posteriormente em torno da política migratória brasileira. Relatos do período situam os haitianos em um "limbo burocrático", porque o governo

5 Os textos midiáticos consultados e citados do ano de 2011 e parte das de 2012 foram acessadas através do Clipping da Radiobrás, para usuários com login e senha. Também estão disponíveis nos portais das mídias citadas. 
brasileiro suspendeu, em fevereiro de 2011, a concessão dos protocolos de refúgio que concedia aos haitianos, alegando a identificação de "uma rota de tráfico humano" (Estado de Minas, 2011a) e o fato de que os haitianos não podiam obter o status de refugiados ${ }^{6}$ (Jornal do Commercio, 2011), tendo que aguardar na fronteira a definição sobre a concessão de um "visto especial" por "questão humanitária" (Camargos e Prates, 2011).

A partir da chegada mais significativa dos imigrantes e do início da inserção laboral de alguns grupos na região Norte - e, depois, Centro-Oeste, Sudeste e Sul - já surgem narrativas apontando a existência, no Acre, de um "excesso de imigrantes ilegais" (Luiz, 2011). Após meados de 2011, outros relatos reforçam esta descrição da chegada dos haitianos pelo viés da "quantidade" e da "ilegalidade". Destacam que "o volume de imigrantes no país fez com o Brasil entrasse no roteiro da diáspora haitiana" (Camargos, 2011) ${ }^{7}$ e qualificam esta imigração como uma "nova maré migratória clandestina" que "não para" (Trezzi, 2011a).

A quantificação da presença dos haitianos, associada à sua condição de "ilegalidade" ${ }^{8}$ acaba contribuindo, em grande parte, para a instauração de uma "semântica do pânico" frente à presença da alteridade migratória. É um recurso que privilegia um enquadramento objetivo e conclusivo das migrações em detrimento da compreensão do seu caráter sociocultural e cidadão, além de fortalecer o protagonismo das nações e governos (e não das sociedades) na gestão e controle da realidade dos movimentos migratórios (Van Dijk, 1997).

Ao tematizarem o movimento inicial mais significativo da chegada dos haitianos, ocorrido entre 2010 e meados de 2011, as narrativas vão constituindo e cristalizando uma descrição deles como "vítimas da miséria" e da devastação, a quem "a pobreza ronda a vida". Os haitianos são aqueles que "fogem" do "terremoto, pobreza, epidemia de cólera, fome e violência" (Trezzi, 2011a). São "es-

6 Os tratados internacionais, assim como a legislação brasileira, consideram refugiados apenas aqueles que são vítimas de perseguição em seu país (por motivos políticos, religiosos, étnicos). Daí a criação, pelo governo brasileiro, da modalidade de visto humanitário para atender à imigração haitiana, o que, em certo sentido, é indicativo da própria inadequação das políticas migratórias brasileiras que vai pautar o debate na mídia.

7 Seriam 1.500 haitianos em 2011, ingressando via Tabatinga/AM, segundo dados atribuídos à Polícia Federal (Camargos, 2011).

8 Pela perspectiva da "cidadania universal", defendido por ativistas das migrações, nenhum migrante seria considerado "ilegal", "irregular" ou "clandestino" fora de seu país de origem e não enfrentaria restrições jurídicas ao acesso à documentação, trabalho, saúde etc. 
perançosos", buscam no aliado Brasil "refúgio, sobrevivência, oportunidades de trabalho", "melhores condições de vida", e "dinheiro para mandar aos familiares que ficaram para trás" (Rocha e Aranha, 2011; Camargos e Prates, 2011; Sabadini, 2011; Estado de Minas, 2011b). Mas "chegam com fome, sede, sem dinheiro e pedindo de tudo", em "um êxodo que atormenta as autoridades e comove entidades humanitárias" (Trezzi, 2011a).

Na dimensão da alteridade de um Outro (Haiti) frente a um Nós (Brasil), as narrativas vitimam os haitianos como indivíduos e povo, associando-os a uma realidade de pobreza e catástrofe. Ao chegar ao Brasil, eles enfrentam dificuldades, mas encontram uma situação "melhor do que no Haiti". O jornal Correio Braziliense descreve-a assim:

A situação dos haitianos é tão dramática e dependente da boa vontade dos brasileiros que ninguém fica à vontade com a ideia de ser fotografado. Temem que as fotos mostrem a situação de miséria em que vivem e que os familiares, no Haiti, descubram que o sonho de uma vida melhor ainda está distante (Correio Braziliense, 2011).

\section{A "invasão haitiana" do Brasil}

À tônica inicial das narrativas midiáticas sobre a imigração haitiana ao Brasil somam-se outros discursos que vão enfatizar o quanto a chegada dos haitianos expõe as fragilidades da política migratória brasileira e da atuação da esfera pública governamental no atendimento aos imigrantes. Defendem maior "coordenação" e organização para lidar com a imigração e uma postura no tratamento aos estrangeiros que os veja "como causa da riqueza cultural, social e econômica" e não "como problema" (Pinto, 2011).

A política migratória brasileira e a atuação governamental passam a ser mais diretamente discutidas no final de 2011, a partir de relatos indicando um novo movimento de chegada de haitianos pelos estados do Amazonas e do Acre - que se intensificará na virada para 2012. As críticas partem tanto de indivíduos e entidades voluntárias que atuam no acolhimento aos haitianos quanto das próprias mídias. No primeiro caso, os atores reivindicam um maior envolvimento e responsabilidade dos governos - federal e estaduais - em ações de "inclusão" e "integração dos haitianos à sociedade brasileira", alertam "para o 
risco de uma crise humanitária", e criticam a retórica de "boas vindas" do discurso governamental, cuja "atuação prática" teria se limitado a conceder vistos humanitários, enquanto o atendimento efetivo aos imigrantes seria feito "exclusivamente" por "missionários evangélicos, igrejas católicas e instituições da sociedade civil" (Farias, 2011). No segundo caso, um conjunto de outras críticas, provenientes das próprias mídias, ou de vozes que através delas ganham visibilidade vão apontar, no começo de 2012, para a necessidade de controle da entrada de haitianos. É neste contexto que emerge um novo quadro de sentido a partir do qual algumas narrativas passarão a interpretar esta imigração. O que antes era enunciado como "fuga" do Haiti, agora passa a ser narrado como "invasão" ao Brasil.

Diferentes relatos, apontam a "chegada em massa de imigrantes do Haiti" ou a "invasão haitiana" na região norte do País, após a entrada de "centenas de refugiados" a Tabatinga/AM e, sobretudo, a Brasileia/AC, entre o final de 2011 e o começo de 2012 (Carvalho, 2012a; Lima, 2012). A interpretação de "invasão" é sustentada por descrições referenciando a "superlotação de refugiados" e a "situação dramática" de haitianos, particularmente no Acre. Tal situação teria levado organizações humanitárias e de apoio às migrações a cobrar melhorias das "condições básicas de vida" dos imigrantes até que sejam "capazes de se manter". Teria levado também os governos estadual e federal a iniciar "um plano para transferir os haitianos para outros grandes centros do país", onde teriam emprego (Carvalho, 2012a; Lima, 2012).

As narrativas do período reafirmam a perspectiva de "ilegalidade" dessa imigração, em alguns casos a partir da comparação na forma como os haitianos são tratados pelo Brasil e pelos países vizinhos: Equador, Colômbia, e, sobretudo, Peru e Bolívia - "os dois corredores de chegada dos imigrantes ilegais". Os relatos enfatizam que estes países não aceitam "a entrada de haitianos ilegalmente, sem visto", nem dão a eles "ajuda humanitária", "ao contrário do Brasil", onde "a entrada ilegal continua, mas eles não são expulsos: obtêm visto humanitário e conseguem tirar carteira de trabalho e CPF para morar e trabalhar no Brasil" (Carvalho, 2012b).

A decisão do governo federal de estabelecer uma cota de 100 vistos/mês a haitianos, a serem emitidos na embaixada brasileira no Haiti, insere-se nesse 
contexto - de narrativas da "invasão" e de uma nova "entrada ilegal de cerca de 500 haitianos" (Frayssinet, 2012) - e vai suscitar vários discursos de apoios e críticas. A ação governamental e os discursos que the sucedem vão evidenciar, a partir de então, o quanto o enquadramento da "invasão" polariza posicionamentos públicos distintos sobre os sentidos da imigração haitiana no Brasil e sobre possíveis conteúdos de uma política migratória que diferentes atores consideram adequada ao novo contexto.

De um lado, posicionamentos como o apoio explícito à medida governamental por parte do jornal Zero Hora, que, em editorial do dia 15/01/2012, defende o "controle do ingresso de haitianos ao país" (Zero Hora, 2012). De outro, um conjunto de outros atores da sociedade civil, que destacam a "situação humanitária e de solidariedade internacional" envolvida no recebimento aos haitianos e o desafio posto ao Brasil de "aplicar a solidariedade que defende como política" quando brasileiros migram a outros países. Também enfatizam o quanto a "diáspora haitiana coloca [a] política imigratória brasileira em xeque" (Frayssinet, 2012), acusando-a de "promoção de imigração seletiva" e defendendo"a necessidade de amplas reformas nas instituições voltadas para a absorção de imigrantes" (Thomaz e Nascimento, 2012; Fórum Social, 2012).

\section{Políticas migratórias em debate}

Se, no começo de 2013, algumas narrativas atribuem ao "surto de imigração" "ilegal" de haitianos a responsabilidade pela criação de "um grave problema no Acre" - que levou o então governador Tião Viana (PT) a decretar "situação de emergência social", em 09 de abril de 2013, e a cobrar sensibilidade e responsabilidade do governo federal no "seu papel institucional e constitucional" de definidor de políticas migratórias (Marcel e Natani, 2013; Damé, 2013) -, no início de 2014, novos relatos reforçam o enquadramento da "invasão" haitiana. No contexto de um novo movimento de entrada de haitianos - cerca de 70 por dia em Brasileia/ AC (Éboli, 2014) -, narrativas evocam a "falta de infraestrutura do abrigo ocupado pelos imigrantes e a escassez de mantimentos", a situação de "calamidade pública" e a necessidade de "fechamento de fronteiras" (Stochero, 2014). Além da "invasão", associam a imigração haitiana a "problema", "chegada massiva", "descontrole" por parte das autoridades, e "ilegalidade" por parte dos imigrantes". 
Agravada pelas enchentes que isolaram o Acre, a situação culmina com o fechamento do abrigo pelo governo do Acre, em abril de 2014, e o envio à cidade de São Paulo de ônibus com aproximadamente 800 haitianos, dos quais cerca de 200 foram acolhidos pela Missão de Paz ${ }^{9}$, entidade confessional que mantém a Casa do Migrante, no centro da cidade. A chegada dos haitianos a São Paulo desencadeia uma disputa política, com ampla visibilidade midiática, envolvendo dois governadores: Geraldo Alckmin (PSDB), de São Paulo, que acusa de "irresponsável" o governo acriano por "não ter avisado" sobre o envio de haitianos a São Paulo, e Tião Viana (PT), do Acre, que acusa a "elite paulista" de promover o"racismo" e a "higienização" (Estarque, 2014).

A dimensão de descontrole e risco que volta a marcar, em 2014, a cobertura midiática sobre o ingresso de haitianos sugere a reinstauração de uma ambiência securitária e criminalizadora que visa o controle dessa imigração, ao mesmo tempo em que contribui para expor, no âmbito do debate público, as repercussões da intervenção geopolítica do Brasil no Haiti. Ressurgem, assim, indagações sobre a responsabilidade e atuação do Estado e governo brasileiro nos processos de recepção e permanência desses imigrantes, implantação de políticas migratórias efetivas (BBC Brasil, 2014) e aprovação de nova lei de imigração adequada à atual realidade migratória do país ${ }^{10}$.

Organizações de apoio às migrações vinculadas à Igreja Católica, redes de imigrantes e instituições acadêmicas, têm se mobilizado, principalmente através da internet, para reivindicar um tratamento humanizado à imigração haitiana por parte do governo e da própria mídia. Trata-se de contradiscursos ao enquadramento da "invasão", provenientes de atores atuantes na defesa e promoção dos direitos dos migrantes e refugiados, como é o caso dos integrantes do Núcleo Interdisciplinar de Estudos Migratórios (NIEM) ${ }^{11}$. Em carta intitulada "Invasão" de haitianos? - Sobre o uso irresponsável do termo pela imprensa" e dirigida ao jornal O Globo ${ }^{12}$ em janeiro de 2014, membros do NIEM criticam o uso

9 Estimativa da Prefeitura de São Paulo (Estarque, 2014).

10 Em substituição ao Estatuto do Estrangeiro em vigor desde a época ditadura. Propostas de nova lei já estão em discussão no âmbito do governo federal, do Congresso Nacional e do Senado.

11 Núcleo de pesquisas e debates sobre as migrações no Brasil e no mundo, existente desde 2000 e sediado na UFRJ.

12 A carta, não publicada pelo Globo, está acessível, dentre outros, no site do Observatório da Imprensa. Ver: Povoas Neto (2014). 
recorrente de "terminologia securitária e criminalizante", enfatizam a necessidade de mudanças nas políticas relacionadas a imigrantes e de implantação de "uma política imigratória aberta ao futuro" (Povoas Neto, 2014). A carta segue na mesma linha de dois manifestos produzidos por organizações de apoio às migrações em 2012 (Fórum Social [...], 2012) e 2013 (CDHIC, 2013), ao questionar, dentre outros aspectos, a existência de critérios de seletividade na definição dos grupos migratórios desejados e não desejados pelo Brasil, a partir dos quais migrantes brancos e europeus, que continuam a chegar ao país, não têm sido considerados um "problema", ao contrário do que se observa em relação aos haitianos (Belchior, 2014).

Além dessas, outras mobilizações da sociedade brasileira ganham visibilidade nas mídias. Paralelo a algumas manifestações racistas e xenofóbicas (YouTube, 2012) há um conjunto de iniciativas e ações de solidariedade da população, incluindo outros grupos migratórios estabelecidos em São Paulo. Realizam campanhas de doações de roupas, alimentos e produtos de higiene pessoal e mobilização de voluntários para atendimento emergencial, na sede da Missão de Paz, dos imigrantes haitianos recém-chegados à capital paulista (Belchior, 2014), de onde muitos partem para outras cidades e estados.

\section{Considerações finais}

Ao analisar o tratamento da imigração de haitianos na mídia noticiosa brasileira nos primeiros anos da presença da diáspora haitiana no Brasil (2011- 2014), constatamos uma transformação no enquadramento midiático. O quadro de sentido mobilizado incialmente para interpretar a imigração haitiana ao país uma "fuga" do Haiti, da "miséria" e do "desastre" - é substituído por outro - o de "invasão haitiana" ao Brasil, que passa a gerar e respaldar discursos defendendo a necessidade de controle de ingresso dos haitianos. A interpretação de "invasão", porém, não é unânime. Os sentidos dessa imigração e da presença haitiana no país são disputados por diferentes atores, impulsionando o questionamento da política migratória e a necessidade de sua atualização.

As disputas de sentido em torno da imigração haitiana instauradas na mídia brasileira no período analisado colaboram para reafirmar que os espaços midiáticos são lugares de construção e proposição de modos de vivenciar a al- 
teridade representada pelos imigrantes. Nesse sentido, são também instâncias de debate e formulação de políticas migratórias envolvendo a cidadania das migrações internacionais. As narrativas e enquadramentos sobre a imigração haitiana aqui analisados evidenciam que a crescente presença da diversidade cultural dos imigrantes no Brasil, a partir de 2008, têm mobilizado, nas mídias, embates envolvendo sociedade civil, governos, acadêmicos, ativistas dos direitos humanos e as próprias organizações midiáticas envolvendo diferentes posicionamentos no marco das políticas específicas orientadas à mobilidade humana.

\section{Referências}

AUDEBERT, Cédric. La diaspora haïtienne: vers l'émergence d'un territoire de la dispersion? In: CÉLIUS, Carlo A. (dir.). Le défi haïtien: économie, dynamique sociopolitique et migration. Paris: L'Harmattan, 2011. p.193-212.

BBC BRASIL. Atitude 'amigável' do governo atrai haitianos. In: BBC Brasil, 28 abril 2014. Disponível em: <http://www.bbc.com/portuguese/noticias/2014/04/140426 haiti saopaulo Ik.shtml>. Acesso em: 17 dez. 2014.

BELCHIOR, Douglas. Os haitianos são o problema ou o problema é a fata de uma política migratória que respeite os imigrantes. Nota do Centro de Direitos Humanos e Cidadania do Imigrante e Grito dos Excluídos Continental. In: Carta Capital, São Paulo, 26 abril 2014. Disponível em: <http://negrobelchior.cartacapital. com.br/os-haitianos-sao-o-problema-ou-o-problema-e-a-falta-de-umapolitica-migratoria-que-respeite-os-imigrantes/>. Acesso em: 17 dez. 2014.

CAMARGOS, Daniel. Ou quase pretos, ou quase brancos. In: Estado de Minas, Belo Horizonte, 07 novembro 2011, editoria Política. Disponível em: < http://clipping. radiobras.gov.br/clipping/novo/>. Acesso em: 17 dez. 2014.

CAMARGOS, Daniel; PRATES, Maria Clara. Brasil é esperança para haitianos. In: Estado de Minas. Belo Horizonte, 13 março 2011. Editoria Nacional. Disponível em: <http://clipping.radiobras.gov.br/clipping/novo/>. Acesso em: 17 dez. 2014.

CARVALHO, Cleide. Acre sofre com invasão de imigrantes do Haiti. In: O Globo, São Paulo, 01 janeiro 2012a, seção País. Disponível em: <http://oglobo.globo.com/ brasil/acre-sofre-com-invasao-de-imigrantes-do-haiti-3549381>. Acesso em: 24 jul. 2013.

CARVALHO, Cleide. Peru e Bolívia, vizinhos do Brasil, negam ajuda a haitianos. In: $\mathbf{0}$ Globo, 08 janeiro 2012b. Disponível em: < http://oglobo.globo.com/brasil/peru- 
bolivia-vizinhos-do-brasil-negam-ajuda-haitianos-3598470\#ixzz3KDcORkGr>. Acessado em: 26 Nov. 2014.

CAVALCANTI, Leonardo; OLIVEIRA, Antonio Tadeu; TONHATI, Tânia. (Orgs.). A Inserção dos Imigrantes no Mercado de Trabalho Brasileiro. Brasília: Cadernos do Observatório das Migrações Internacionais, 2014.

CDHIC - Centro de Direitos Humanos e Cidadania do Imigrante. Organizações lançam manifesto pela humanização da cobertura midiática sobre as migrações no Brasil. In: CDHIC, São Paulo, 03 maio 2013. Disponível em: <http://www. cdhic.org.br/?p=1040>. Acesso em: 17 dez. 2014.

COGO, Denise;SOUZA, Maria Badet. Guia das migrações transnacionais e diversidade cultural para comunicadores - Migrantes no Brasil. Bellaterra: Institut de la Comunicación-UAB/Instituto Humanitas - Unisinos, 2013. Disponível em: $<$ https://www.academia.edu/3255909/COGO Denise BADET Maria. Guia das Migra\%C3\%A7\%C3\%B5es Transnacionais e Diversidade Cultural para Comunicadores - Migrantes no Brasil. Bellaterra InCom-UAB IHU 2013>. Acesso em: 14 mai. 2015.

COGO, Denise. Haitianos no Brasil - comunicação e interação em redes migratórias transnacionais. Chasqui - Revista Latinoamericana de Comunicación. Quito, n. 125, marzo, 2014. p. 23-32.

CORREIO BRAZILIENSE. O sonho dos haitianos. In: Correio Braziliense, 31 julho 2011. Editoria Brasil. Disponível em: <http://clipping.radiobras.gov.br/clipping/ novo/>. Acesso em: 17 dez. 2014.

DAMÉ, Luiza. Governo fará força tarefa para regularizar situação dos haitianos no Acre. In: O Globo, Brasília, 10 abril 2013. Disponível em: <http://oglobo.globo.com/ brasil/governo-fara-forca-tarefa-para-regularizar-situacao-dos-haitianos-noacre-8081373 >. Acesso em: 17 dez. 2014.

ÉBOLI, Evandro. Acre quer fechar fronteira para evitar excesso de haitianos no Brasil. In: O Globo, Rio de Janeiro, 16 janeiro 2014. Disponível em: < noblat.oglobo.globo.com/noticias/noticia/2014/01/acre-quer-fechar-fronteirapara-evitar-excesso-de-haitianos-no-brasil-520994.html>. Acesso em: $17 \mathrm{dez}$. 2014.

ESTADO DE MINAS. Brasil barra 300 haitianos. In: Estado de Minas, Belo Horizonte, 12 março 2011 a. Editoria Nacional. Disponível em: <http://clipping.radiobras.gov. br/clipping/novo >. Acesso em: 17 dez. 2014.

. Haitianos esperançosos. In: Estado de Minas, Belo Horizonte, 31 julho $2011 \mathrm{~b}$. Editoria Nacional. Disponível em: <http://clipping.radiobras.gov.br/clipping/ novo>. Acesso em: $16 \mathrm{dez} 2014$. 
ESTARQUE, Marina. No centro de disputa política, haitianos vivem incerteza em São Paulo. In: DW Brasil, São Paulo, 30 abril 2014. Disponível em: <http://www. dw.com/pt/no-centro-de-disputa-pol\%C3\%ADtica-haitianos-vivem-incertezaem-s\%C3\%A3o-paulo/a-17603711>. Acesso em: 17 dez. 2014.

FARIAS, Elaíze. Estado brasileiro nunca deu apoio a imigrantes haitianos, diz voluntária do Amazonas. In: A crítica. Manaus, 24 Novembro 2011. Disponível em: < $\underline{\text { http:// }}$ acritica.uol.com.br/amazonia/Amazonia-Amazonas-Manaus-Estado-brasileiroimigrantes-Amazonas-voluntaria 0 596940664.html>. Acesso em: 26 nov. 2014.

FRANÇA, Vera Veiga, SILVA, Terezinha; VAZ, Geraldo Frances Fonseca. Enquadramento (Verbete). In: FRANÇA, Vera Veiga; MARTINS, Bruno Guimarães.; MENDES, André Melo (Org.). Grupo de Pesquisa em Imagem e Sociabilidade (GRIS): trajetória, conceitos e pesquisa em Comunicação. 1ed. Belo Horizonte: PPGCOM-UFMG, 2014, v. 1, p. 82-85.

FRAYSSINET, Fabiana. Diáspora haitiana coloca política imigratória brasileira em xeque. In: Site Opera Mundi. Rio de Janeiro, 17 janeiro 2012. Disponível em: < http:// operamundi.uol.com.br/conteudo/noticias/19241/diaspora+haitiana+coloca +politica+imigratoria+brasileira+\%20em+xeque.shtml>. Acesso em: 26 nov. 2014.

FORUM SOCIAL PELOS DIREITOS HUMANOS E INTEGRAÇÃO DOS MIGRANTES NO BRASIL. Manifesto em defesa dos direitos humanos de imigrantes haitianos. In: Fórum [...], São Paulo, 16 janeiro 2012. Disponível em: <https://fsidhsmigrantes. wordpress.com/page/2/>. Acesso em: 17 dez. 2014.

GOFFMAN, Erving. Les cadres de l'experience. Paris. Les Éditions de Minuit.1991.

JORNAL DO COMMÉRCIO. Haitianos barrados na fronteira do Brasil. In: Jornal do Commércio, Recife, 12 março 2011. Disponível em: <http://clipping.radiobras. gov.br/clipping/novo/>. Acesso em: 16 dez. 2014.

LIMA, Wilson. Haitianos refugiados no Acre são enviados a SP e Porto Alegre. In: Portal iG Maranhão, 09 janeiro 2012. Disponível em: <http://ultimosegundo.ig.com. br/brasil/haitianos-refugiados-no-acre-sao-enviados-a-sp-e-porto-alegre/ n1597559789374.html>. Acesso em: 26 Nov. 2014.

LUIZ, Edson. Mão de obra haitiana. In: Correio Braziliense, Brasília, 15 março 2011. Disponível em: <http://clipping.radiobras.gov.br/clipping/novo/>. Acesso em: 17 dez. 2014.

MARCEL, Yuri; NATANI, Rayssa. Acre decreta situação de emergência social por causa de surto de imigração. In: Portal G1, Acre, 09 abril 2013. Disponível em: < http:// g1.globo.com/ac/acre/noticia/2013/04/acre-decreta-situacao-de-emergenciasocial-por-causa-de-surto-de-imigracao.html>. Acesso em: 17 dez. 2014. 
PINTO, Paulo Silva. Americanos do Haiti. In: Correio Braziliense, 19 março 2011. Coluna Entrelinhas. Disponível em: <http://clipping.radiobras.gov.br/clipping/ novo/>. Acesso em: 17 dez. 2014.

POVOAS NETO, Helion. Sobre o uso irresponsável de um termo. In: Observatório da Imprensa, São Paulo, 21 janeiro 2014, edição 782. Disponível em: < http:// observatoriodaimprensa.com.br/direito-de resposta/ ed782 sobre o uso irresponsavel de um termo/>. Acesso em: 17 dez. 2014.

QUÉRÉ, Louis. Entre o facto e o sentido: a dualidade do acontecimento. Trajectos. Lisboa, n. 6, 2005, p. 59-75.

ROCHA, Leonel; ARANHA, Ana. O que fazer com os imigrantes do Haiti? In: Revista Istoé. São Paulo, 05 fevereiro 2011. Seção Brasil. Disponível em: <http://clipping. radiobras.gov.br/clipping/novo/>. Acesso em: 17 dez. 2014.

SABADINI, Tatiana. País recebe 500 haitianos ilegais. Correio Braziliense, Brasília, 18 fevereiro 2011. Editoria Mundo. Disponível em: <http://clipping.radiobras.gov. br/clipping/novo/>. Acesso em: 17 dez. 2014.

STOCHERO, Tahiane. Entrada diária de haitianos triplica e quadro preocupa, dizgoverno do Acre In: Portal G1, São Paulo, 15 janeiro 2014. Disponível em: < http://g1.globo.com/ ac/acre/noticia/2014/01/em-7-dias-entrada-de-haitianos-triplica-e-acre-temetragedia.html>. Acesso em: 17 dez 2014.

THOMAZ, Omar Ribeiro e NASCIMENTO, Sebastião. Europeus bem-vindos, haitianos barrados. In: Folha de S. Paulo, São Paulo, 21 janeiro 2012. Opinião. Disponível

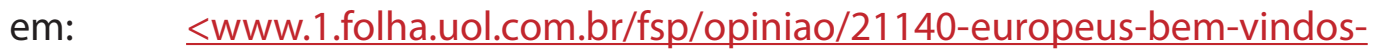
haitianos-barrados.shtml>. Acesso em: 26 abr. 2012.

TREZZI, Humberto. Maré de haitianos chega ao Brasil. In: Zero Hora, Porto Alegre, 12 junho 2011(a). Disponível em: <http://clipping.radiobras.gov.br/clipping/ novo/>. Acesso em: 16 dez. 2014.

. Migrantes procuram benefícios de refugiados. In: Zero Hora, Porto Alegre, 12 junho 2011 (b). Disponível em: <http://clipping.radiobras.gov.br/clipping/ novo/>. Acesso em: 16 dez. 2014.

VAN DIJK, Teun A. Racismo y análisis crítico de los medios. Buenos Aires: Paidós, 1997.

XIMENES, Dimas; ALMEIDA, Guilherme. Brasil de volta ao imaginário de imigrantes. Labor- Revista do Ministério Público do Trabalho. V. II, n. 5, 2014, p. 26-32.

YOUTUBE.Não paraa invasão haitiana no Brasil.In:YouTube, 12abril 2012.Disponívelem: $<$ https://www.youtube.com/watch?v=LwqljLi-de4\&https\%3A\%2F\%2Fwww. youtube.com\%2Fwatch\%3Fv=PGsVscFv4tke>. Acesso em: 02 dez. 2014. 
ZERO HORA. O Brasil e os haitianos. In: Zero Hora, Porto Alegre, 15 janeiro 2012. Editorial. Disponível em: <http://wp.clicrbs.com.br/editor/2012/01/12/ editorial-apoia-controle-do-ingresso-de-haitianos-no-pais-voce-concorda/?to po=13,1,1,13???0000000 >. Acesso em: 02 dez. 2014.

Recebido em: 14/09/2015

Aceito em: 7/10/2015

Endereço dos autores:

Denise Cogo <denisecogo2@gmail.com>

Escola Superior de Propaganda e Marketing

Rua Dr. Álvaro Alvim, 123 - Vila Mariana.

CEP: 04018-010

São Paulo/SP - Brasil

(11) $5085-4500$

Terezinha Silva <terezinhasilva@yahoo.com $>$

Universidade Federal de Minas Gerais

Av. Pres. Antônio Carlos, 6627 - Pampulha.

CEP: 31270-901

Belo Horizonte/MG - Brasil

(31) 3409-5000 